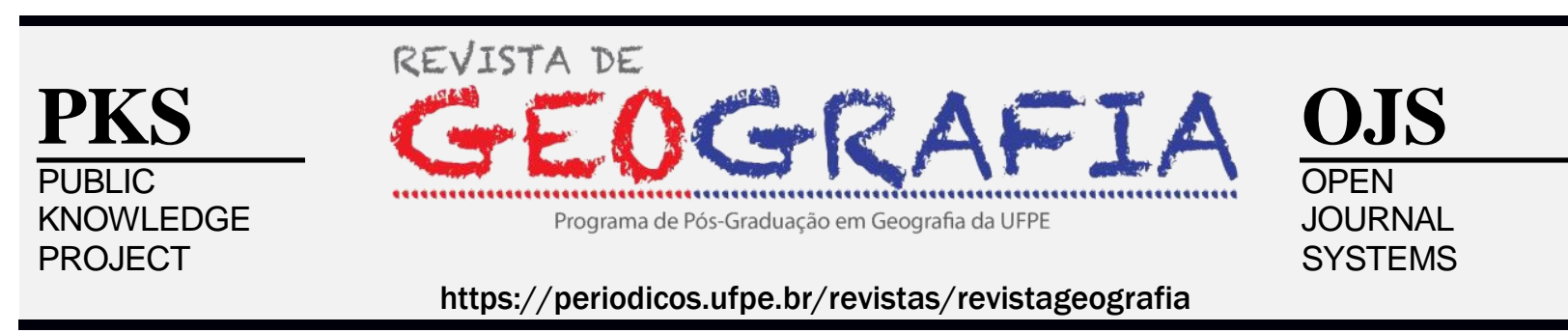

\title{
USO DO SIG NA CLASSIFICAÇÃO DAS UNIDADES DE RELEVO NO MUNICÍPIO DE TOROPI - RS
}

\author{
Bruno Casanova Vilaverde Gomes ${ }^{1}$, Daniélli Flores Dias², Luís Eduardo de Souza \\ Robaina $^{3}$, Romario Trentin ${ }^{4}$
}

\begin{abstract}
${ }^{1}$ Mestrando do Programa de Pós-Graduação em Geografia da Universidade Federal de Santa Maria. engenheirovilaverde@gmail.com.

${ }^{2}$ Doutoranda do Programa de Pós-Graduação em Geografia da Universidade Federal de Santa Maria. daniellidias08@gmail.com

${ }^{3}$ Professor Titular do Departamento de Geociências da Universidade Federal de Santa Maria. lesrobaina@yahoo.com.br

${ }^{4}$ Professor Adjunto do Departamento de Geociências da Universidade Federal de Santa Maria. romariotrentin@gmail.com
\end{abstract}

Artigo recebido em 15/08/2018 e aceito em 13/05/2019

\begin{abstract}
RESUMO
O relevo é um dos principais definidores das unidades ambientais, de modo que sua compartimentação se apresenta com estreita relação à distribuição dos demais atributos de gênese da paisagem. O objetivo desse estudo é estabelecer uma compartimentação do relevo do município de Toropi, localizado no estado do Rio Grande do Sul, com a utilização de bases cartográficas em formato digital associadas ao Sistema de Informação Geográfica, através de métodos automatizados e com a integração de variáveis morfométricas. A análise considerou os seguintes parâmetros: hipsometria, declividade e amplitude da encosta. A classificação permitiu descrever as diferentes unidades de relevo e aponta suas principais características, identificando áreas de maior ou menor fragilidade, quando associada ao substrato litológico. A classificação feita por meio do Sistema de Informação Geográfica, com dados altimétricos SRTM, mostrou ser bastante eficiente, pois representa as características observadas em campo.
\end{abstract}

Palavras-chave: Geomorfologia; Relevo; Sistema de Informação Geográfica.

\section{USE OF GIS IN THE CLASSIFICATION OF RELIEF UNITS IN THE MUNICIPALITY OF TOROPI - RS}

\begin{abstract}
The landforms are one of the main definers of the environmental units, so that its compartmentalization presents it self with close relation to the distribution of the other attributes of genesis of the landscape. The objective of this study is to establish a compartmentalization of the relief in the municipality of Toropi located in state of Rio Grande do Sul, with the use of cartographic bases in digital format associated with Geographic Information System, through automated methods and with the integration of morphometric variables. The analysis considered the following parameters: hypsometry, slope and slope amplitude. These classifications describe the different relief units and point out their main characteristics, identifying areas of greater or lesser fragility when associated to the lithological substrate. The classification using the Geographic Information System, with SRTM altimetric data, proved to be quite efficient, since it represents the characteristics observed in the field.
\end{abstract}

Keywords: Geomorphology; Relief; Geographic Information System. 


\section{INTRODUÇÃO}

A geomorfologia faz uso do estudo do relevo como intermédio de representação gráfica e espacial do terreno. Conforme Rezende e Salgado (2011), um dos principais definidores das unidades ambientais é o relevo, de maneira que sua compartimentação se apresenta frequentemente com estreita relação à distribuição dos demais atributos de gênese da paisagem.

As unidades de relevo fornecem informações para compreensão da dinâmica do terreno, servindo como ferramentas para tomada de decisões frente as condições ambientais e o uso racional dos recursos naturais, permitindo a compreensão dos componentes da superfície terrestre, da mesma forma que estabelece áreas de potencialidades e fragilidades do meio ambiente (ROSS, 1990; 2006; FLORENZANO, 2008; ROBAINA, et al., 2010; SCCOTI, 2015).

As formas de relevo se definem pelo ordenamento espacial de superfícies homogêneas com relação a unidades básicas do relevo, e sua classificação faz uso de diferentes parâmetros como a altitude, declividade e forma das encostas, etc. (ROSS, op. cit.).

Robaina et al (2015) definem que as formas de relevo e as litologias constituem o substrato físico onde se desenvolvem as atividades humanas e dessa forma, trabalhos de zoneamentos que determinam unidades homogêneas são imprescindíveis para o entendimento dos processos geomorfológicos e como as ações geomorfológicas podem interferir no meio. Esses trabalhos que cruzam as informações referentes ao relevo e as litologias são chamados de mapeamentos morfolitológicos. Além disso, destaca-se também que os parâmetros de relevo representam importantes fatores condicionantes aos processos de dinâmicas superficiais, permitindo, desse modo, levantamentos fundamentais para o auxílio no planejamento e ordenamento territorial.

O uso e ocupação do solo é uma temática essencial para o planejamento ambiental, retratando as atividades antrópicas e reconhecendo os impactos sobre o meio. A paisagem pode ser representada por marcas naturais ou com influências antrópicas, que podem sofrer maior ou menor alteração no ambiente em virtude suas características de origem (DE NARDIN, 2009).

Nessa concepção, estes estudos surgem como uma forma de avaliar adequadamente os recursos naturais, com a compartimentação da área de estudo em função de suas características naturais e sua inter-relação com as atividades antrópicas (DE NARDIN e ROBAINA, 2006). 
Com a obtenção das devidas informações das condições naturais e antrópicas da superfície, é possível identificar as necessidades do meio às potencialidades ambientais, dando origem a uma ocupação ordenada, promovendo alternativas para um melhor aproveitamento do ambiente. Desta forma, o trabalho contribui para tomadas de decisões em relação ao planejamento ambiental regional.

A partir dos Sistemas de Informações Geográficas (SIG’s), a obtenção dos atributos do relevo passou a ser um procedimento de aquisição mais acessível, com a parametrização da morfologia do relevo representando o processo de extração de atributos quantitativos por meio da topografia. Conforme Muñoz (2009), é possível descrever de forma quantitativa as formas da superfície da Terra por meio de equações aplicadas a modelos numéricos de representação altimétrica.

Com o passar do tempo, observamos a evolução do desenvolvimento tecnológico, que, nos fornecem ferramentas para um processamento de dados cada vez mais eficiente, contribuindo para sanar disfunções ligadas aos recursos naturais. As novas tecnologias fornecem subsídios para o pesquisador analisar e interpretar as alterações que ocorrem sobre o relevo ao longo do tempo, desenvolvendo ações que possam reduzir os impactos ao meio ambiente.

A partir do surgimento das geotecnologias é possível, por meio de um banco de dados georreferenciado, inserir e executar a interpolação de informações referentes a natureza, viabilizando o ordenamento dos dados, sua organização e execução de diversas e complexas análises.

Conforme Trentin (2007), a utilização da cartografia nos permite uma análise integrada, por meio de registros indiretos, aerofotogramas e imagens de satélite, possibilitando a obtenção, registro e análise das alterações do relevo do terreno para a elaboração de um trabalho visando à ocupação mais adequada do meio.

A aplicação da geotecnologia para o planejamento do uso racional dos recursos naturais vem se difundido cada vez mais e por consequência, facilita o desenvolvimento de estudos ambientais. Hoje detemos de uma ampla tecnologia que fornece a utilização de ferramentas e produtos capazes de facilitar e agilizar o levantamento, mapeamento e análise dos recursos naturais existentes.

Diante desse contexto, o presente artigo objetiva estabelecer uma compartimentação do relevo do município de Toropi, com apoio de técnicas de geoprocessamento e a utilização de SIG. A área de estudo localiza-se na região centro-oeste do estado do Rio Grande do Sul 
(Figura 1), entre as coordenadas geográficas de 29²4'30” e 29³2'19” (latitude sul) e $54^{\circ} 25^{\prime} 14^{\prime \prime}$ e $54^{\circ} 10^{\prime} 51^{\prime \prime}$ (longitude oeste), limitando-se ao norte com o município de Jari, ao sul com o município de São Pedro do Sul, a leste com Quevedos e a oeste com Jaguari e Mata, totalizando uma área de 202,98 km².

Figura 1. Localização da área de estudo.

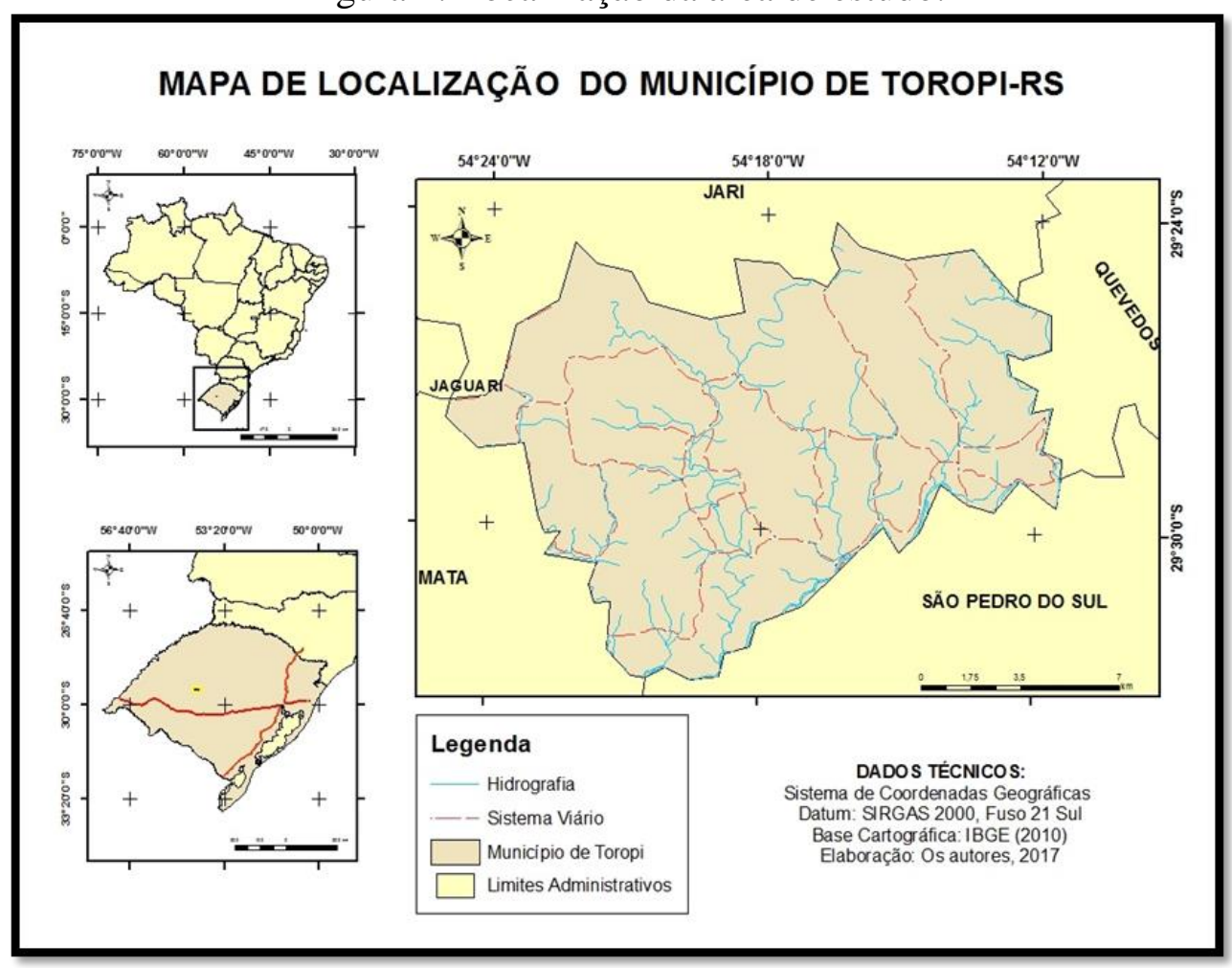

Fonte: Elaborado pelos autores (2017).

\section{METODOLOGIA}

Os procedimentos metodológicos para a realização do trabalho iniciaram com a revisão bibliográfica e compilação de materiais cartográficos acerca da área de estudo. Para sua elaboração foi utilizada a Base Cartográfica Vetorial Contínua do Rio Grande do Sul na escala 1:50.000, organizada por Hasenack e Weber (2010), assim como as imagens de RADAR da missão Shuttle Radar Topography Mission (SRTM), com resolução espacial de 90 metros obtidos através do banco de dados disponibilizado pela United States Geological Survey (USGS). O Sistema de Referência é o Universal Transversal de Mercator (UTM), com Sistema de Referência SIRGAS 2000, Fuso 21, Hemisfério Sul.

Para a confecção dos mapas fez-se o uso do software ArcGIS ${ }^{\circledR} 10.1$ desenvolvido pela ESRI. Os parâmetros morfométricos considerados neste trabalho foram: hipsometria, 
declividade e amplitude da encosta. Através das ferramentas "topo to raster" e "slope" do ArcGIS $^{\circledR} 10.1$ foram elaborados os mapas de hipsometria e declividade, respectivamente.

Para a criação do mapa hipsométrico utiliza-se como metodologia a fórmula de Sturger (1926), na qual consiste em calcular qualquer número de classes, definida através da equação:

$$
K=1+\log 2(N)
$$

Sendo o $\mathrm{K}$ o número de classes, e o $\mathrm{N}$ a amplitude; cálculo este que resultou na determinação de seis classes para o município de Toropi, o que permitiu estabelecer uma divisão a cada 50 metros.

Para a elaboração do mapa de declividades usa-se como base os limites discutidos pelo Instituto de Pesquisas Tecnológicas do estado de São Paulo (IPT, 1981), e pelo Laboratório de Geologia Ambiental da Universidade Federal de Santa Maria (LAGEOLAM/UFSM), estabelecendo quatro intervalos: $\langle 5 \% ; 5$ a $15 \% ; 15$ a $30 \%$ e $>30 \%$. O valor de $5 \%$ representa áreas de baixa declividade e onde se registram o início dos processos erosivos; o valor de $15 \%$ representa a faixa que define o limite máximo para o emprego da mecanização na agricultura.

As amplitudes foram calculadas através de dois perfis traçados em diferentes posições no município, considerando a altitude e declividade determinadas. Para as amplitudes utilizou-se a indicação do IPT que utiliza 100 metros como limite.

$\mathrm{Na}$ classificação das unidades de relevo foi realizada através dos atributos morfométricos identificados conforme a Tabela 1 .

Tabela 1. Unidades morfológicas, utilizadas para a classificação.

\begin{tabular}{ccc}
\hline $\begin{array}{c}\text { Amplitudes das } \\
\text { encostas }\end{array}$ & $\begin{array}{c}\text { Declividade das } \\
\text { encostas }\end{array}$ & \multicolumn{2}{c}{ Unidades } \\
\cline { 2 - 3 } & $<5 \%$ & Altitude $<300 \mathrm{~m} \quad$ Altitude $>300 \mathrm{~m}$ \\
\cline { 2 - 3 } & $5-15 \%$ & Áreas planas \\
\hline $\mathbf{1 0 0} \mathbf{m}$ & $>15 \%$ & Colinas de \\
& $>15 \%$ & Altitude \\
\hline $\mathbf{1 0 0} \mathbf{m}$ & Fonte: Adaptado do Instituto de Pesquisas Tecnológicas (IPT, 1981)
\end{tabular}


A partir da obtenção dos referidos mapas e análise feita por imagens de satélites disponíveis pelo software ArcGIS ${ }^{\circledR} 10.1$ com o serviço de Basemap - World Imagery constitui-se de um banco de dados com imagens de satélite e escalas em alta resolução espacial.

A definição das formas das encostas foi definida por meio do plano e perfil de curvatura. O mapa de perfil de curvatura apresenta as curvaturas côncava e convexa, e o mapa de plano de curvatura retrata as curvaturas divergentes e convergentes.

Os parâmetros de curvatura foram gerados por meio do software ArcGIS, aplicando a ferramenta "curvature", sendo definidas por meio de um modelo digital de elevação, sendo possível obter as curvaturas: côncavo-convergente $(\mathrm{Cc} . \mathrm{Ct})$, convexo-convergente $(\mathrm{Cx} . \mathrm{Ct})$, côncavo-divergente (Cc. Dt), e convexo-divergente (Cx. Dt.) (Figura 2).

Figura 2. Modelos de curvatura das encostas.

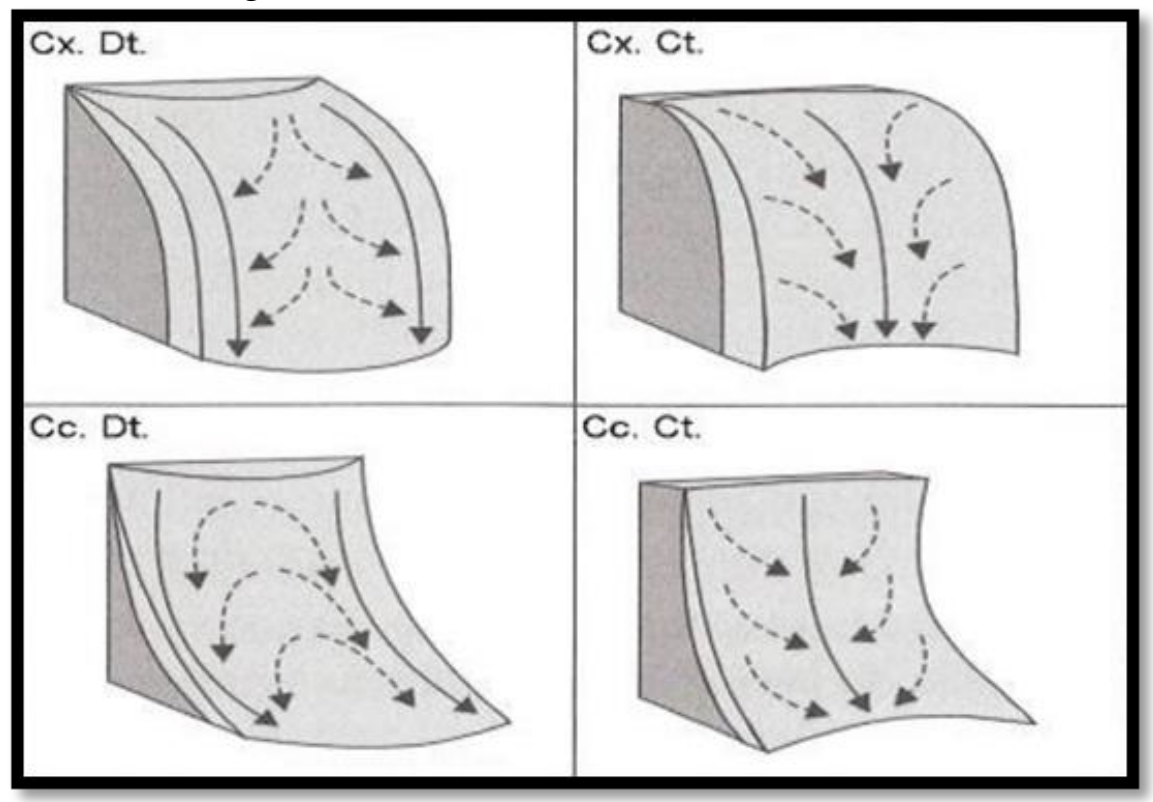

Fonte: Summerfield (1997).

O mapa das unidades morfolitológicas corresponde a associação dos elementos contidos nos levantamentos de relevo e litologias, onde ocorreu a sobreposição nos layers no ambiente do software ArcGIS, possibilitando a vetorização manual das unidades morfolitológicas. 


\section{RESULTADOS E DISCUSSÕES}

\section{Parâmetros morfométricos}

O município de Toropi apresenta um relevo diversificado, comumente observado na transição do Rebordo do Planalto para a Depressão Central (ROBAINA, et al., 2010). A amplitude altimétrica é de 325 metros, com sua menor cota de 92 metros, localizada na porção sul do município, junto ao rio Toropi, e a maior cota é de 417 metros na porção noroeste e nordeste da área, junto ao Rebordo do Planalto ou em porções do Planalto da Serra Geral, como pode ser observado no mapa hipsométrico da Figura 3.

Figura 3. Mapa hipsométrico do município de Toropi - RS.

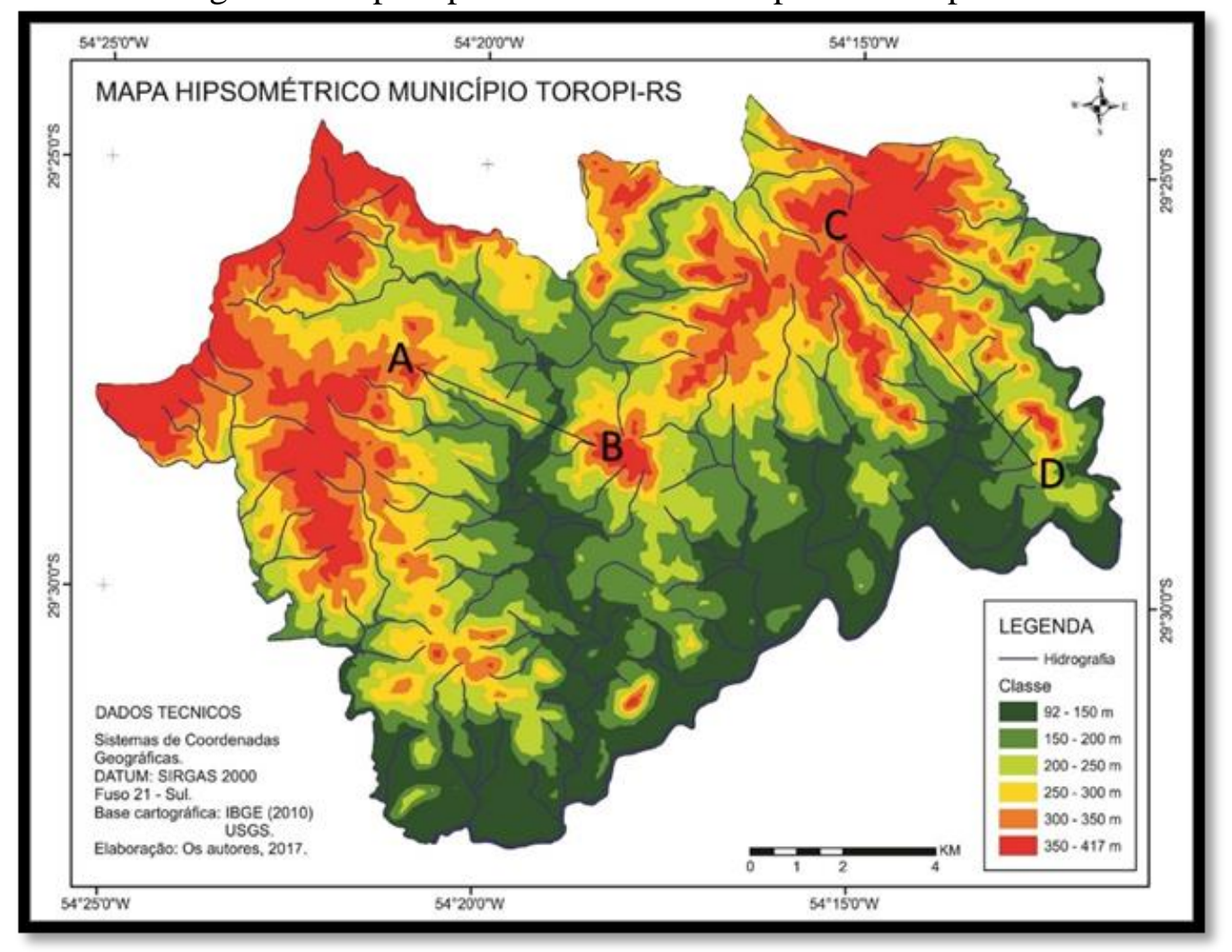

Fonte: Elaborado pelos autores (2017).

A classe hipsométrica predominante, no município de Toropi, situa-se no intervalo de 92 a 150 metros, representando 20,24\% da área avaliada, estando associada a drenagem e planícies de inundação, situada na Depressão Periférica. Segue a classe entre 150 a 200 metros, que corresponde a 19,23\%; a classe de 200 a 250 representando 17,44\%, e que ocorrem, predominantemente, na porção central e leste do município; a classe de 250 a 300 
metros com percentual de 16,09\%, dando início a faixa de transição da Depressão Periférica para o Rebordo do Planalto; e por fim, a classe de menos representativa $(12,79 \%)$ que se encontra no intervalo de 350 a 417 metros, sendo composta pelas áreas de cabeceiras de drenagens.

A declividade é um fator fundamental para o estudo dos processos de dinâmica superficial que acontecem nas vertentes. Para o município de Toropi, foram definidas quatro classes de declividade: entre 0 e $5 \%$, entre 5 e $15 \%$, entre 15 e $30 \%$ e superiores a $30 \%$, que estão espacializadas no mapa da Figura 4.

Figura 4. Mapa de declividade do município de Toropi - RS.

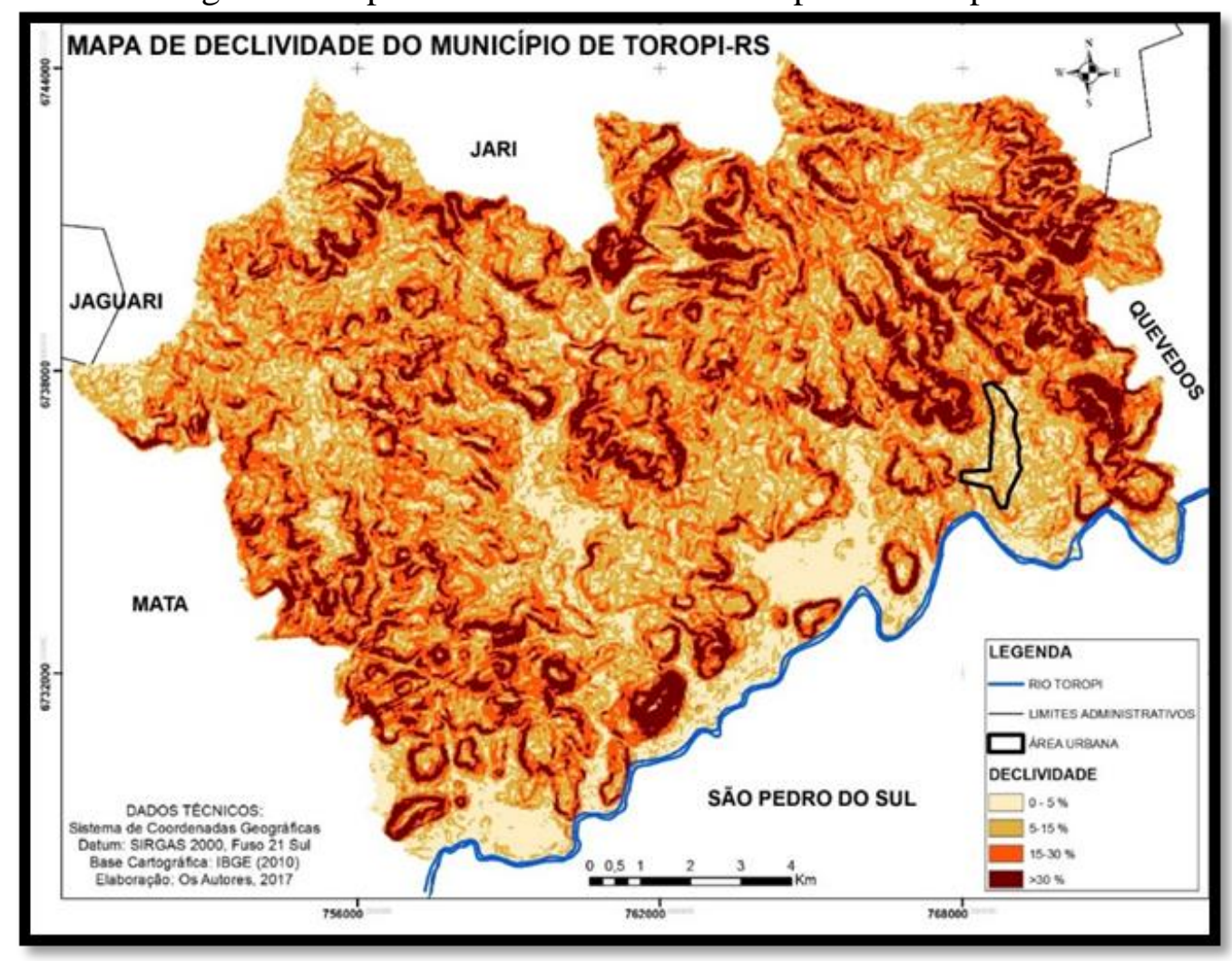

Fonte: Elaborado pelos autores (2017).

As declividades menores que 5\% representam as áreas planas, compreendendo a 3,96\% do total da área em estudo. Esta classe se distribui nas porções sul, sudoeste, estando principalmente, associada às drenagens. Essas áreas são suscetíveis a inundações, junto às planícies, onde ocorrem depósitos de sedimentos. 
As variações entre 5\% e 15\% representam 11,55\% do município e caracterizam um relevo ondulado, onde processos erosivos podem ser atuantes e o limite superior marca a inclinação máxima para uso de maquinários.

As variações entre $15 \%$ e $30 \%$ correspondem a 37,79\% da área de estudo e possui um relevo ondulado e muito ondulado, com formas escarpadas e íngremes, definindo áreas com suscetibilidade a processos erosivos e movimentos de massa.

Por fim, as variações maiores que $30 \%$, totalizam $46,67 \%$ da área estudada e representam áreas onde processos morfogenéticos como transporte e movimentos de massa são significativos.

A amplitude das encostas podem ser observados através do traçado dos perfis topográficos A-B e C-D (Figuras 5 e 6). O perfil topográfico A-B, foi traçado no sentido NOSE, onde o ponto A foi traçado na porção noroeste do município, com altitudes em torno de 400 metros, e realizando corte na bacia do Arroio Sampaio, com altitude média de 100 metros, retornando a altitudes mais elevadas no ponto B localizado a sudeste do município.

O perfil topográfico C-D também foi traçado no sentido NO-SE, e seu ponto C iniciou com uma altitude média de 400 metros na porção noroeste, fazendo um corte até o ponto D, chegando em uma área de menor altitude localizada na porção sudeste do município.

Figura 5. Perfil Topográfico A-B.

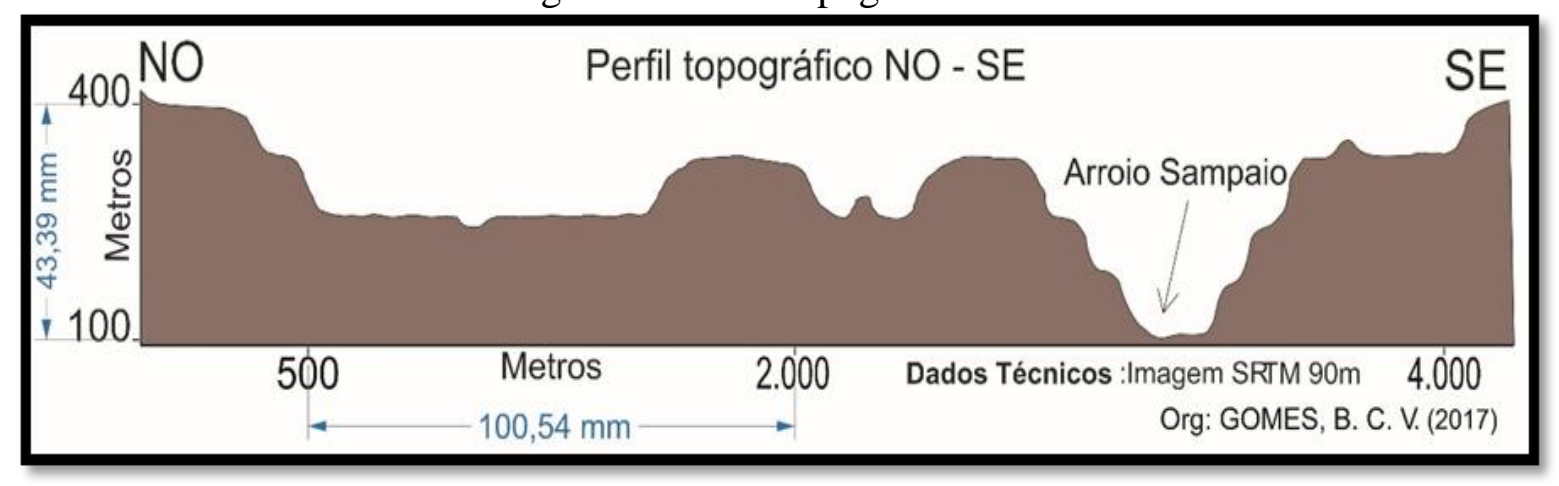

Fonte: Elaborado pelo autor (2017). 
Figura 6. Perfil Topográfico C-D.

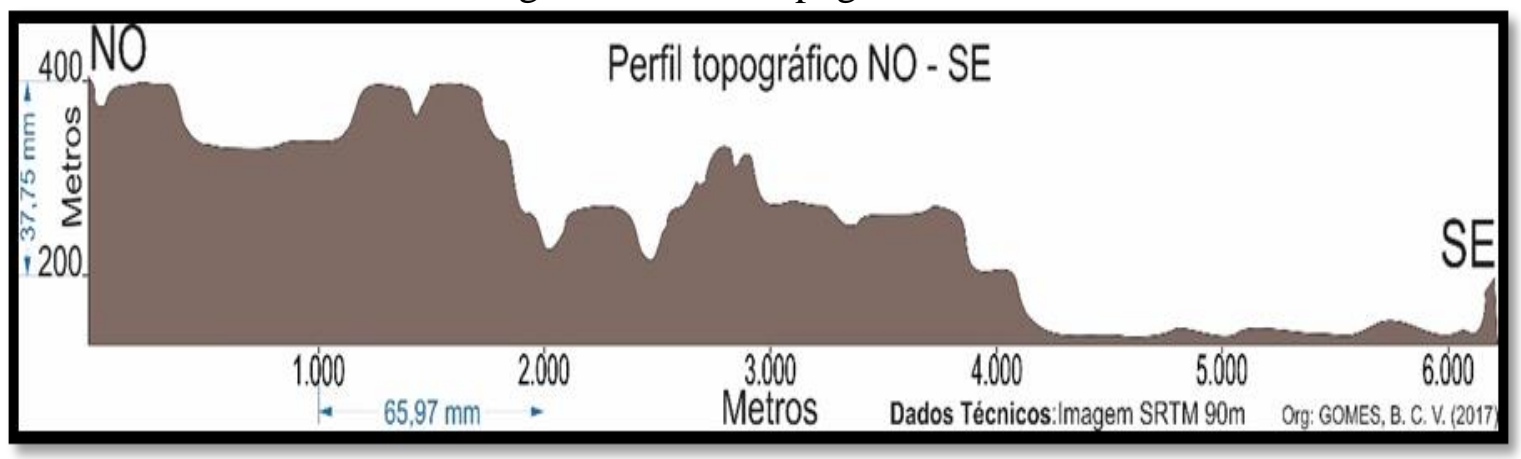

Fonte: Elaborado pelo autor (2017).

\section{Forma das encostas}

As encostas se estabelecem como um elemento da superfície terrestre inclinado em relação a horizontal, retratando um gradiente e uma orientação no espaço. Associando-se de acordo com a declividade e curvatura no perfil e no plano. A análises do perfil de curvatura da vertente refere-se ao caráter convexo e côncavo do terreno, e o plano de curvatura da vertente, dividem-se em convergentes e divergentes.

O perfil de curvatura apresenta maior percentual para as vertentes côncavas correspondendo a $50,27 \%$ e $49,72 \%$ para as vertentes convexas. Estes fatores estão diretamente ligados a velocidade do escoamento superficial de água sobre o terreno.

As vertentes convexas estão difundidas em todo território do município de Toropi (Figura 7), sendo possível observar a quebra do relevo em declives superiores a 15\%. Elas possuem como característica sua marcação dos topos até a média vertente, influenciando de forma significativa na energia do escoamento superficial no terreno. Desta forma, com o aumento do escoamento superficial ocorre a diminuição da taxa de infiltração de água no solo e consequentemente o aumento do tempo de chegada do fluxo nos canais de drenagem.

As vertentes côncavas também podem ser observadas em toda a área do município, tendo sua marcação da meia vertente até sua base, localizando-se em porções do relevo de baixo declive. Nessas áreas ocorre a atuação de processos erosivos, tendo ligação direta com a vazão do curso d'água no canal de drenagem. 
Revista de Geografia (Recife) V. 36, No. 2, 2019 - ISSN: 2238-6211

Figura 7. Mapa do perfil de curvatura do município de Toropi.

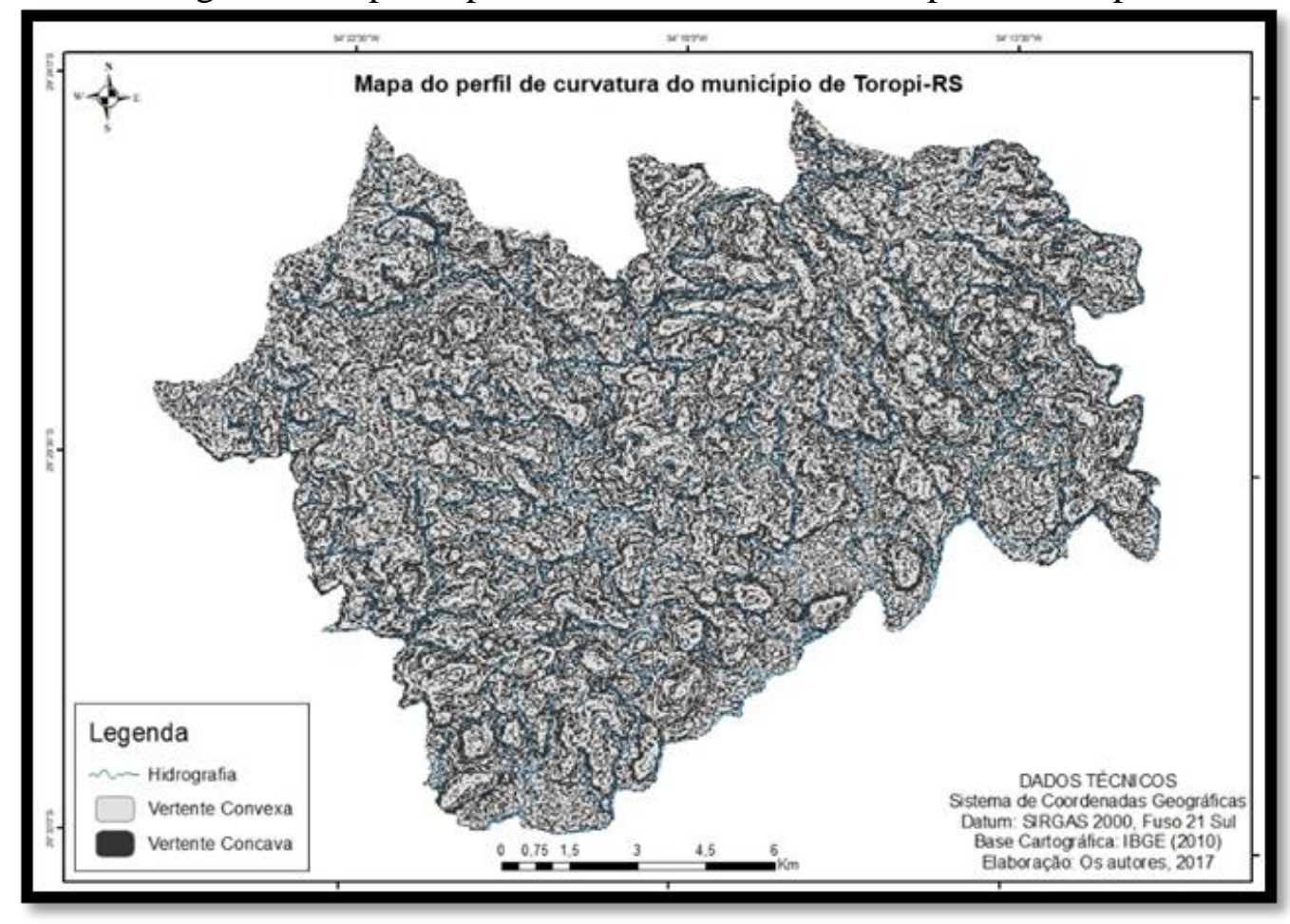

Fonte: Elaborado pelo autor (2017).

Com relação ao plano de curvatura (Figura 8), destaca-se que as vertentes convergentes correspondem a 52,83\% do total da área de estudo, e as vertentes divergentes tem representam $47,17 \%$.

As vertentes convergentes são caracterizadas pela concentração do fluxo do escoamento superficial na encosta, sendo associadas aos canais de drenagem, e originam o aparecimento de canais fluviais que contribuem para o abastecimento das drenagens. Por sua vez, nas vertentes divergentes, ocorre a associação dos topos das vertentes a meia encosta, tendo com isso, uma dispersão do fluxo do escoamento sobre o terreno. 
Revista de Geografia (Recife) V. 36, No. 2, 2019 - ISSN: 2238-6211

Figura 8. Mapa do plano de curvatura do município de Toropi.

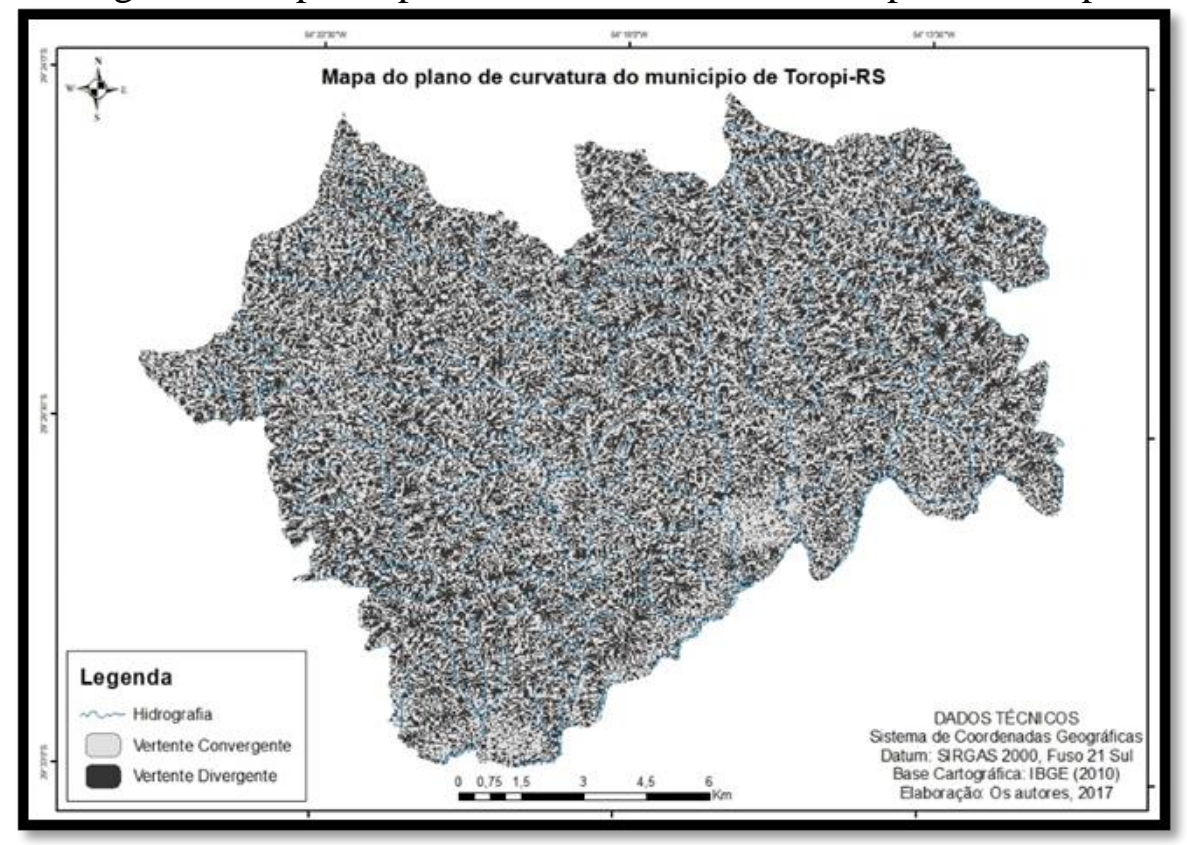

Fonte: Elaborado pelo autor (2017).

Por meio da associação entre o perfil de curvatura e o plano de curvatura, obteve-se quatro feições referentes as formas das vertentes: côncavo-convergente, côncavo-divergente, convexo-convergente, convexo-divergente, conforme representa a Figura 9.

Figura 9. Mapa das formas de vertentes do município de Toropi.

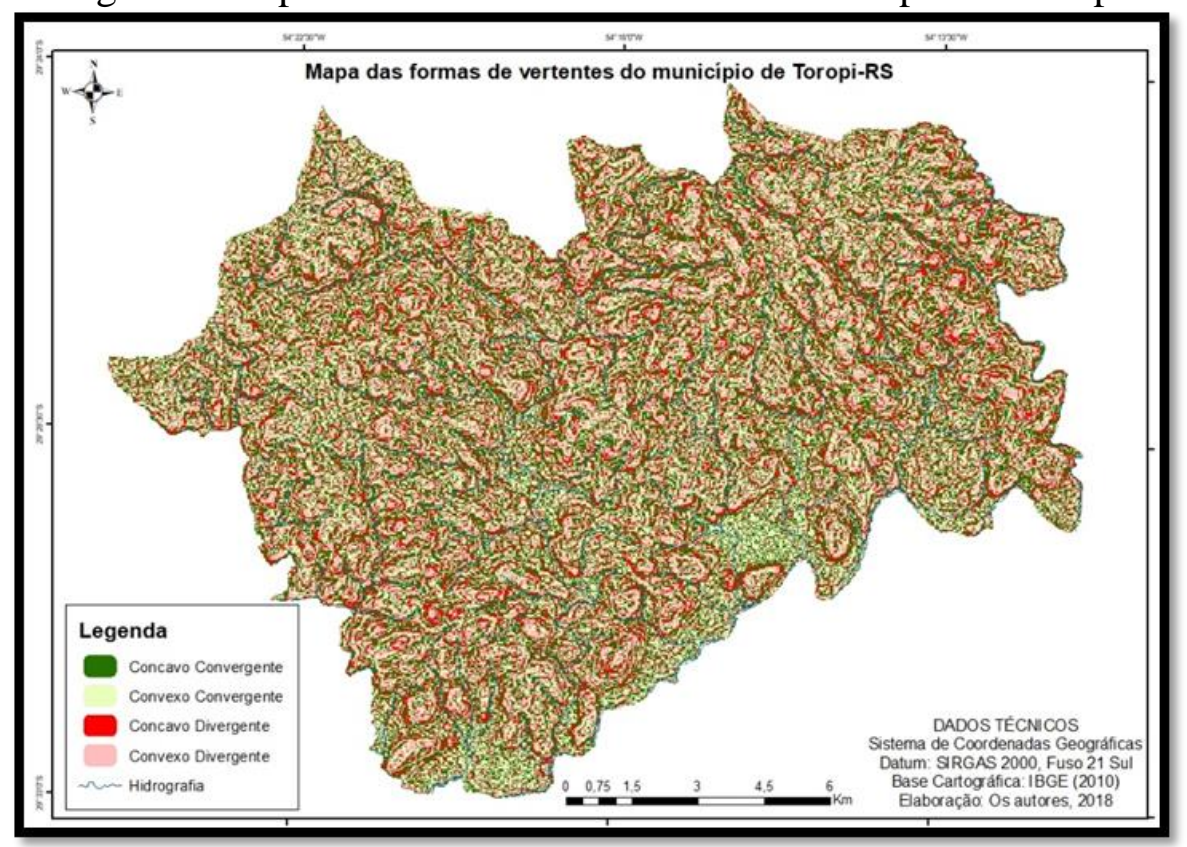

Fonte: Elaborado pelo autor (2017). 
A forma de vertente côncavo-convergente, espacializa-se em todo território do município, representando $34,62 \%$, sendo a forma de vertente mais expressiva da área de estudo. Este tipo de vertente se caracteriza em função da concentração dos fluxos sobre a vertente, e pode ser observada principalmente junto ao leito dos canais fluviais.

A forma côncavo-divergente corresponde a $17,61 \%$ do total da área de estudo, e distribui-se em todo o município, podendo ser observada na região próxima ao segmento médio até a base da vertente.

A forma da vertente convexo-convergente representa $15,53 \%$ e distribui-se em praticamente todo o município, onde é possível observar uma concentração associada em porções do relevo próximo ao leito do rio Toropi. Essas vertentes têm como característica a concentração do fluxo de escoamento, o que ocasiona maior escoamento superficial.

Corresponde a $32,24 \%$ a forma de convexo-divergente espacializa-se por todo o município. Este tipo de vertente pode ser observada próximas ao topo à meia vertente e caracterizam-se pela dispersão do fluxo.

\section{Unidades de Relevo}

Por meio da análise dos parâmetros morfométricos do relevo do município de Toropi RS, foram definidas cinco unidades de relevo em porções do terreno com formas homogêneas: Colinas de Altitude, Associação de Morros e Morrotes, Áreas Planas, Colinas e Morros Isolados, espacializados no mapa da Figura 10. 
Figura 10. Mapa de unidades de relevo do município de Toropi.

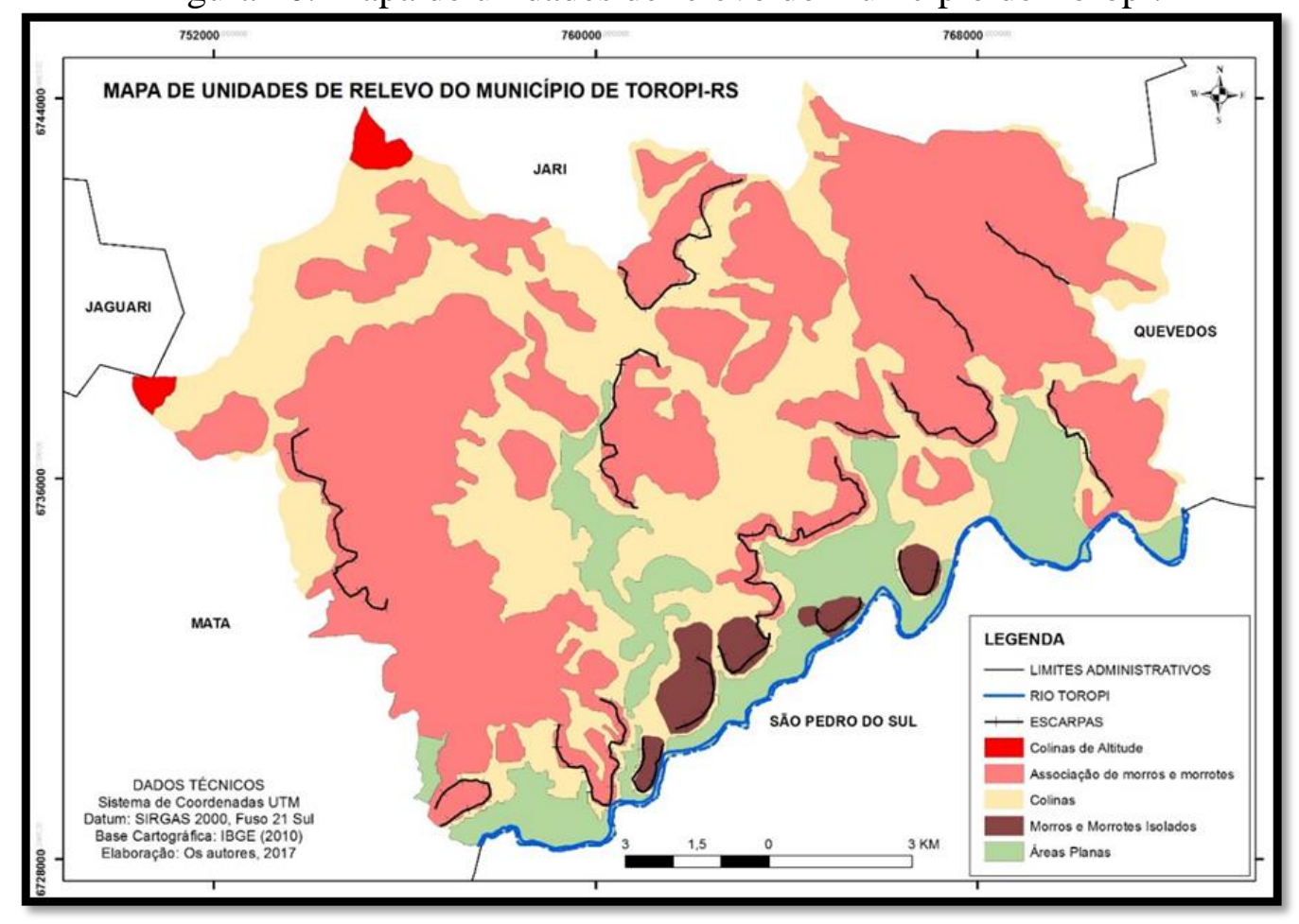

Fonte: Elaborado pelo autor (2017).

A unidade das Colinas de Altitude situa-se a oeste e noroeste no município de Toropi, sendo a menor unidade presente na área de estudo, correspondendo a apenas $0,71 \%$. Apresenta uma amplitude altimétrica de 20 a 40 metros, e a declividade nos intervalos de 5\% a $15 \%$.

A unidade da Associação de Morros e Morrotes se distribui em grande parte do município, com maios incidência a leste, nordeste, norte, oeste e sudoeste, totalizando 50,90\% do total da área de estudo. As formas de Morrotes apresenta declividades superiores a $15 \% \mathrm{e}$ amplitude inferiores aos 100 metros, que na área de estudo varia de 60 a 100 metros. E nos Morros, a declividade também é superior aos 15\%, mas sua amplitude altimétrica é predominantemente superior aos 100 metros, variando de 100 a 240 metros.

A unidade das Colinas apresenta formas com amplitudes altimétricas inferiores a 100 metros e declividades em torno de 5\%. Essa unidade está distribuída por toda extensão da área de estudo, com maior densidade ao centro e noroeste do município, contemplando 34,26\%. Essas formas de relevo se caracterizam por apresentar o surgimento de incisões lineares (ravinas e voçorocas) nas porções da vertente com fluxo convergente.

A unidade de Morros e Morrotes Isolados marca o recuo do Rebordo do Planalto. Se caracterizam por formas que apresentam amplitude altimétrica superior a 100 metros para os 
Morros Isolados, variando de 100 a 220 metros, e inferior a 100 metros para Morrotes Isolados, com amplitude altimétrica de 40 a 60 metros. Essas unidades localizam-se ao sul do município, juntos a planície do rio Toropi, totalizando $2,41 \%$ do total da área de estudo.

A unidade das Áreas Planas compõe o relevo associado a segmentos de canais fluviais, principalmente ao rio Toropi, distribuindo-se ao centro, sul e sudeste da área de estudo, correspondendo a 11,86\% da área de estudo. Nas áreas planas, a declividade é inferior a 5\%.

\section{Compartimentação morfolitológica}

A compartimentação morfolitológica do município de Toropi foi realizada a partir do cruzamento entre as informações referentes as formas de relevo e das litologias, resultando em seis unidades morfolitológicas para a área de estudo: Áreas Planas com Depósitos Recentes, Colinas Onduladas em rochas sedimentares, Colinas Onduladas em rochas vulcânicas, Colinas de Altitudes em rochas vulcânicas, Associação de Morros e Morrotes em rochas vulcânicas, Morros e Morrotes Isolados em rochas vulcânicas, que são espacializados na Figura 11.

Figura 11. Mapa morfolitológico do município de Toropi.

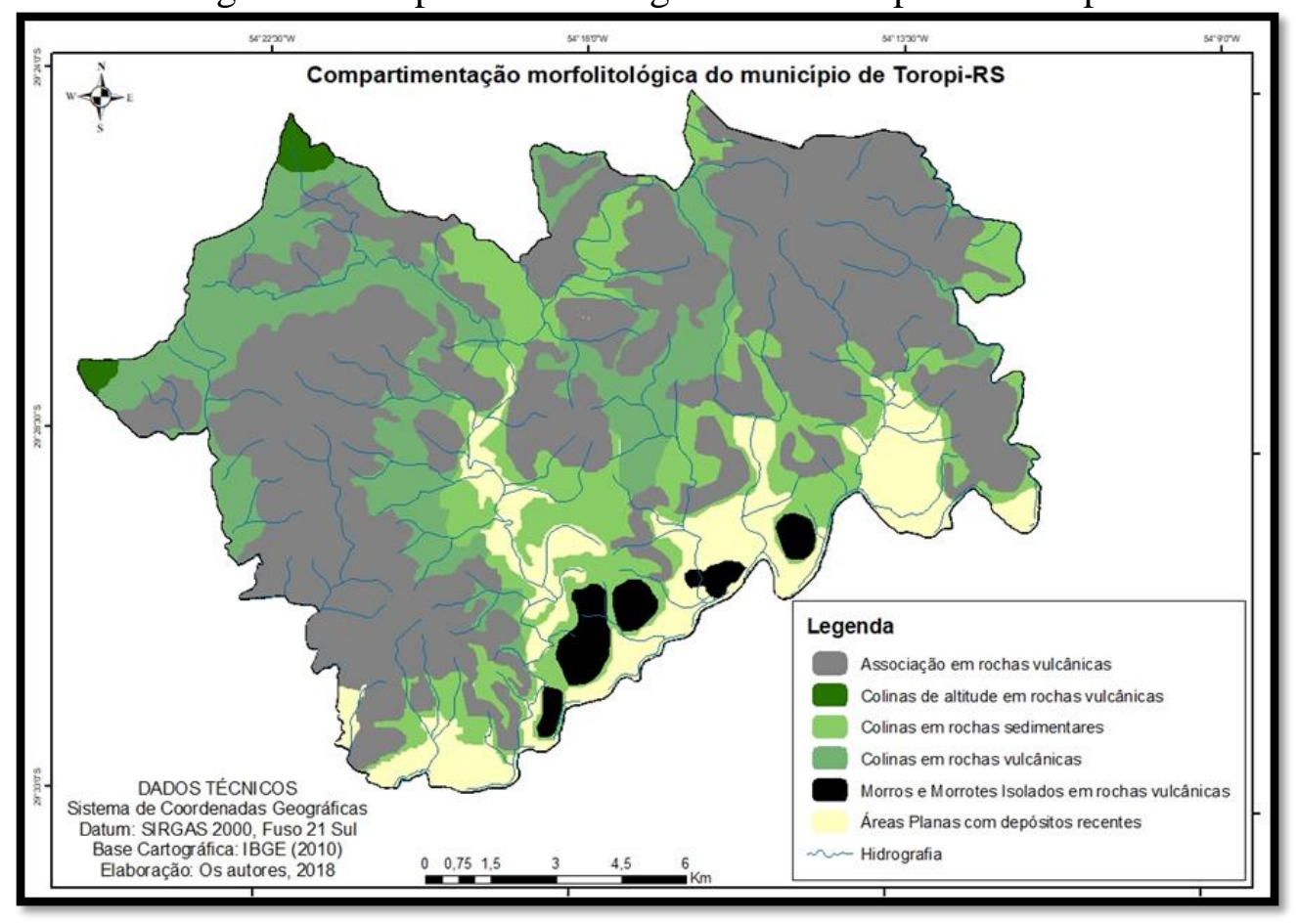

Fonte: Elaborado pelo autor (2017). 
A unidade das Áreas Planas com Depósitos Recentes ou comumente denominadas como planícies de acumulação ou inundação, abrangem as porções com altitudes inferiores a 150 metros e declividades menores que 5\%, configurando uma área onde os principais eventos que nela ocorrem são os de deposição de sedimentos fluviais, constituindo as litologias denominadas depósitos recentes. Essa unidade corresponde a 11,86\% do total da área de estudo. Ocorrem nas áreas de acumulação, junto a planície de inundação do rio Toropi e do arroio Sampaio com seus respectivos afluentes. Esses depósitos recentes (também denominados depósitos aluviais) são compostos por areias grossas, argilas e cascalhos. Nessas áreas a atividade de lavouras de arroz é favorecida.

A unidade morfolitológica das Colinas onduladas em rochas sedimentares, predomina nas porções centro e nordeste totalizando $14,51 \%$ da área de estudo. Suas altitudes variam entre 150 e 350 metros, as declividades variam entre 5 e 15\%, interflúvios curtos e apresentam incisões lineares.

O substrato litológico é constituído por arenitos da Formação Botucatu, que caracteriza-se por apresentar estratificação cruzada de larga escala e que se encontram soterrados ou intercalados nas lavas basálticas da Formação Serra Geral (CPRM, 2007).

Na unidade das Colinas em rochas vulcânicas ocorrem predominantemente na porção centro e noroeste e correspondem a $19,75 \%$ da área do município e apresentam características de altitudes e declividades semelhantes a unidade descrita anteriormente.

Possuem substrato rochoso formado por rochas vulcânicas classificadas como Fácies Gramado CPRM (2007), que são constituídas por derrames de basaltos granulares finos a médios, com coloração que varia do cinza ao preto, com horizontes vesiculares de topo preenchidas por zeolitas, carbonatos, apofilitas e saponita. Possuem estruturas de fluxo e do tipo pahoehoe e intercalações de arenitos intertrápicos similares a Formação Botucatu.

Essas áreas não são de grande extensão, mas permitem o uso para lavouras e criação de gado bovino. As colinas em arenitos são mais suscetíveis a erosão, necessitando de maior utilização de técnicas conservação do solo.

A unidade morfolitológica das Colinas de Altitudes em rochas vulcânicas, ocorre na porção noroeste e oeste do município, em altitudes superiores a 350 metros, declividade entre 5 e $15 \%$, representando apenas $0,71 \%$ da área de estudo. O substrato litológico é constituído por derrames de basaltos granulares, com coloração variando do cinza ao preto, horizontes vesiculares preenchidos e intercalados com arenitos intertrápicos, caracterizando as rochas vulcânicas da Fácies Gramado. 
A unidade da Associação dos Morros e Morrotes Isolados em rochas vulcânicas representam 50,90\% do total da área de estudo, conferindo a unidade morfolitológica mais expressiva. Apresentam altitudes mínimas de 250 metros e declividades superiores a $15 \%$. O substrato litológico dessa unidade é composto por rochas vulcânicas da Fácies Gramado sobre os arenitos eólicos da Formação Botucatu. Em alguns casos, a ocorrência de arenitos intertrápicos geram surgências, permitindo a instalação da vegetação arbórea que formam uma espécie de "anel" ao redor dos morros e morrotes. Essas áreas são as mais suscetíveis aos movimentos de massa e pequenas corridas nas porções convergentes da encosta.

A unidade dos Morros e Morrotes Isolados em rochas vulcânicas localizam-se na porção sul do município, representando $2,41 \%$ do total da área de estudo. Assim como a unidade morfolitológica descrita anteriormente, apresenta substrato litológico composto por rochas vulcânicas da Fácies Gramado sobre o arenito da Formação Botucatu. Essa unidade apresenta altitudes superiores a 200 metros, declividades acima de 30\% e apresentam topos arredondados.

\section{CONSIDERAÇÕES FINAIS}

O presente estudo teve objetivos estabelecidos para a compartimentação do relevo no município de Toropi por meio de ferramentas de SIG's e técnicas de geoprocessamento foram alcançadas. Com isso conclui-se que o uso de materiais cartográficos são essenciais para o desenvolvimento desse tipo de estudo, bem como o uso de parâmetros morfométricos de declividade, hipsometria e amplitude da encosta, pois através desses parâmetros juntamente com as litologias, que se conseguiu distinguir áreas com atributos homogêneos e assim alcançando os mapas finais das formas de relevo e das unidades morfolitológicas.

Dessa maneira este trabalho cria a possibilidade para novos estudos nessa mesma área, com embasamento geomorfológico e ambiental, pois concluiu-se que as formas que o relevo desenvolve sobre a superfície terrestre tem importância significativa para futuros estudos geomorfológicos bem como novos procedimentos.

\section{REFERÊNCIAS}

COMPANHIA DE PESQUISAS E RECURSOS MINERAIS. Gravataí - SH,22-X-C-V, escala 1:100.000: nota explicativa. Porto Alegre: UFRGS/CPRM, 2007. 72p. 
DEMEK, J. Manual of detailed geomorphological mapping. Praga, IGU, Comm Geomorph. Surv. Mapping, 1972. 368p.

DE NARDIN, D. Zoneamento Geoambiental no Oeste do Rio Grande do Sul: um estudo em bacias hidrográficas. 2009. 230f. Dissertação (Mestrado em Geografia)-Universidade Federal do Rio Grande do Sul, Porto Alegre, 2009.

DE NARDIN, D.; ROBAINA, L. E. S. Mapeamento Geomorfológico da Bacia Hidrográfica do Miracatu, Oeste do Rio Grande do Sul. In: VI SIMPÓSIO NACIONAL DE GEOMORFOLOGIA, 2006, Goiânia/GO. Anais... Goiânia/GO: Universidade Federal de Goiás, 2006.

ENVIRONMENTAL SYSTEMS RESEARCH INSTITUTE. ArcGIS ${ }^{\circledR} \quad \mathbf{1 0 . 1}$ License Manager and Installation. Disponível em: <http://desktop.arcgis.com/en/desktop/latest/getstarted/license-manager-guide/license-manager-installation-and-startup.htm/>. Acesso em: 10 mar. 2016.

FLOREnZANO, T. G. Geomorfologia: Conceitos e Tecnologias Atuais. São Paulo: Oficina de Textos, 2008.

HASENACK, H.; WEBER, E. (Orgs.). Base cartográfica vetorial contínua do Rio Grande do Sul - escala 1:50.000. Porto Alegre: Centro de Ecologia da UFRGS, 2010.

INSTITUTO BRASILEIRO DE GEOGRAFIA E ESTATÍSTICA. Malha Municipal do ano de 2010. Disponível em: <http://mapas.ibge.gov.br/bases-e-referenciais/basescartograficas/malhas-digitais>. Acesso em: 18 out. 2015.

INSTITUTO DE PESQUISAS TECNOLÓGICAS DO ESTADO DE SÃO PAULO. Mapa Geomorfológico do Estado de São Paulo. São Paulo. Escala 1:500.000, 1981. 130p.

MUÑOZ, V. A. Análise geomorfométrica de dados SRTM aplicada ao estudo das relações solo-relevo. Dissertação (Mestrado em Sensoriamento Remoto) - Instituto Nacional de Pesquisas Espaciais, São José dos Campos, 2009. 
REZENDE, É, A.; SALGADO, A. A. R. Mapeamento de Unidades de Relevo na Média Serra do Espinhaço Meridional - MG. GEOUSP - Espaço e Tempo, São Paulo, 2011.

ROBAINA, L. E. S. et al. Compartimentação Geomorfológica da Bacia Hidrográfica do Ibicuí, Rio Grande do Sul, Brasil: Proposta de Classificação. Revista Brasileira de Geomorfologia, São Paulo, v. 11, n. 2, p. 11-23, 2010. Disponível em: $<$ http://www.lsie.unb.br/rbg/index.php?journal=rbg\&page=article\&op=view\&path\%5B\%5D= 148>. Acesso em: 12 jan. 2016.

ROBAINA, L. E. S. et al. Zoneamento Morfolitológico da Bacia Hidrográfica do Rio Ibicuí e sua Relação com os Processos Superficiais e o Uso do Solo. Revista Brasileira de Geomorfologia, São Paulo, v. 16, n. 1, p. 63-77, 2015. Disponível em: http://www.lsie.unb.br/rbg/index.php?journal=rbg\&page=article \&op=view\&path $\% 5 \mathrm{~B} \% 5 \mathrm{D}=6$ 30\&path\%5B\%5D=444. Acesso em: 01 abr. 2016.

ROSS, J. L. S. Ecogeografia do Brasil: Subsídios para planejamento ambiental. $1^{\text {a }}$ ed. São Paulo: Oficina de Textos, 2006.

ROSS, J. L. S. Geomorfologia: Ambiente e Planejamento. São Paulo: Contexto, 1990. 85p.

SUMMERFIELD, M. A. Global Geomorphology an introduction to the study of landforms. England: British Library Cataloguing in Publication Data, 1997. 535p.

STURGES, H.; The choice of a class-interval. Journal of the American Statistical Association., v. 21, p. 65-66, 1926.

TRENTIN, R. Definição de unidades geoambientais na bacia hidrográfica do rio Itu Oeste do RS. Dissertação (Mestrado em Geografia)-Universidade Federal de Santa Maria, Santa Maria, 2007.

UNITED STATES GEOLOGICAL SURVEY. Shuttle Radar Topography Mission. Disponível em: <http://srtm.usgs.gov/>. Acesso em: 09 jan. 2016. 